\title{
Association of Blood Groups with Oral Submucous Fibrosis and if any of the Blood Group is Related with an Increased Risk for Oral Submucous Fibrosis
}

\author{
SOBIA SIDDIQUE ${ }^{1}$, SYED MUHAMMAD RAZI ZAIDI ${ }^{2}$, SHAHIDA MAQBOOL ${ }^{3}$, MADIHA INSHA $^{4}$, MUHAMMAD ABUL \\ HASAN ALI ${ }^{5}$, AROOJ KHURSHID 6 \\ ${ }^{1}$ Assistant Professor, Oral Pathology, HBS Medical \& Dental College, Islamabad \\ ${ }^{2}$ Demonstrator, Oral Pathology, Fatima Jinnah Dental College, Karachi \\ ${ }^{3}$ Assistant Professor, Oral Medicine, HBS Medical \& Dental College, Islamabad \\ ${ }^{4}$ Demonstrator, Oral Pathology, HBS Medical \& Dental College, Islamabad \\ ${ }^{5}$ Senior lecturer, Oral medicine, HBS Medical \& Dental College, Islamabad \\ ${ }^{6}$ Demonstrator, Oral Pathology, HBS Medical \& Dental College, Islamabad \\ Correspondence to Dr. Sobia Siddique; Email: sobiawaqar3033@yahoo.com, Ph +92-315-9991457
}

\begin{abstract}
Objective: To assess any association of blood groups with oral submucous fibrosis and if any of the blood group is related with an increased risk for oral submucous fibrosis.

Study Design: Comparative study

Place and Duration of Study: Department Of Oral Pathology, Fatima Jinnah Dental College \& Hospital Karachi, Pakistan from Jan to Dec 2018.

Patients and Methods: Total 100 patients were enrolled in the study in which half were cases where oral sub mucous fibrosis had been diagnosed clinically while remaining half were the controls that were involved in the habit of using tobacco/nuts but had no oral pre malignant lesion. For investigation of blood, samples of blood were taken from both the groups. Odd ration and chi-square test was used to analyze data. A p-value of $<0.05$ was considered statistically significant.

Results: Majority of the individuals in experimental group had "B" blood group followed by "O" "AB" and " $A$ " blood groups.

Conclusion: This study showed that $\mathrm{ABO}$ blood groups have considerable relation with oral submucous fibrosis. Individuals having "B" blood group had 2.18 times increased tendency of having oral submucous fibrosis in contrast with patients who belong to any other blood group.

Keywords: ABO blood group system, Oral Submucous fibrosis, Oral lesions, Oral Squamous Cell Carcinoma
\end{abstract}

\section{INTRODUCTION}

A potentially malignant lesion of oral cavity is known as oral Submucous fibrosis (OSMF) is. It is an unvarying, progressive disease which was firstly explained by Sushrutha (2500-3000 BC) as Vidhari, he reported it like an issue of throat and oral cavity and later in the modern days by Schwartz in 1952 who termed it as "Atropica idiopathica mucosae oris"1. In 1966, Pindborg defined OSMF as, "a menacing, persistent illness affecting any site of mouth and at times pharynx". Though infrequently preceded by and/or related with vesicle development, it is constantly connected with juxtaepithelial inflammatory response followed by a fibroelastic alteration in lamina propria, with epithelial degeneration causing the firmness of oral mucosa and ultimately obscurity in opening mouth and lack of ability to eat and open the mouth².

The epidemiological studies shows that it's common prevalence is in populace of South Asian countries or in immigrants form South Asia to different areas of whole world, owing to the consumption of Areca nut and its array of formulations available in these regions. Around 10-20\% population of the world consume areca nut or it's different preparations. $^{3}$ In a prevalence study conducted on 1774 individuals in Karachi, Pakistan; 765 (43.13\%) cases had OSMF alone, 472 (26.60\%) reported with malignant transformation of OSMF to oral squamous cell carcinoma (OSCC) and 537 (30.27\%) had OSCC alone with no clinically observed $\mathrm{OSMF}^{4}$. In India, frequency of OSMF ranges from 0.2 to $2.3 \%$ for male population while for females it is $1.2-4.6 \% 5$. The likelihood of malignant conversion of OSMF is in the range of $1.9-9 \%$ depending upon the follow up period and the investigative criteria ${ }^{6}$.

The different blood groups describe the difference in serology between individuals depending upon the presence or absence of Agglutinogen present on the surface of red blood cells. ${ }^{1}$ Anderson and Haas in 1984 were the first to narrate the relation between blood groups and likeliness of malignancy. Since then, a variety of studies were carried out to establish this association. In population of Indian subcontinent, patients with blood group $A$ has more proclivity for OSMF and oral carcinoma. ${ }^{7}$ In the current study our aim was assessment of link between the ABO blood groups and OSMF besides further observing if any of the $\mathrm{ABO}$ blood groups is related with an increased risk for OSMF.

\section{PATIENTS AND METHODS}

This was a comparative study, carried out in the Department Of Oral Pathology, Fatima Jinnah Dental College Karachi, Pakistan, between Jan to Dec 2018; after due approval of the ethical review committee. A total of 100 patients were included in the study out of which 50 were OSMF cases that were functionally and clinically diagnosed as per benchmarks given by Haider et al (2000) as stage I, stage II and stage III and 50 control cases were enrolled in this research using convenience sampling 
technique. Medical particulars regarding name, gender, age and unusual habits, for example pan masala chewing without or with tobacco, gutkha, areca nut, simple tobacco, mawa chewing, alcohol consumption and smoking, were noted. In addition period of habits in time (years), incidence of habits per day, method to chew i.e. swallowing or spitting and also period of chewing was recorded. Blood samples were collected from all the patients that constituted the cases and the controls for investigation of their blood group. Analysis of blood group of the patients was made by dropping blood drop on slide and mixing it with anti-A and anti-B sera. When positive agglutinations appeared upon mixing of blood with anti-sera $A$, blood group of that subject was lab bled as $A$ and if agglutinations appeared upon mixing with anti-sera $B$, it was labeled as blood group B. In case no agglutinations appeared, the blood group was labeled as $\mathrm{O}$. But, if agglutinations occurred with both antisera $A$ \& $B$, the blood group was labeled as $A B$. Likewise, positive agglutination response with $R h$ antigen is measured Rh positive or else as $\mathrm{Rh}$ negative. Collected data was statistically processed using SPSS v 21.0, using chi-square and odd ratio and the results were shown in Tabulated form. $P$ value $<0.05$ was taken significant

\section{RESULTS}

In the present study, blood group B was noted to be the most prevalent among cases and controls. Among controls and the cases, distribution of ABO blood groups has been shown in Table 1.

Table I: Characteristics of blood groups in controls and the cases.

\begin{tabular}{|c|c|c|c|}
\hline $\begin{array}{l}\text { Subjects with } \\
\text { Blood Group }\end{array}$ & Cases N (\%) & Control N (\%) & $p$-value \\
\hline 0 & $19(38 \%)$ & $18(36 \%)$ & \multirow{5}{*}{$<0.03$} \\
\hline A & $2(4 \%)$ & $7(14 \%)$ & \\
\hline B & $26(52 \%)$ & $19(38 \%)$ & \\
\hline$A B$ & $3(6 \%)$ & $6(12 \%)$ & \\
\hline Total & $50(100 \%)$ & $50(100 \%)$ & \\
\hline
\end{tabular}

Among controls and the cases odds ratio is 2.18 times higher with blood group $B$ mean high risk of developing OSMF and malignancy, $O$ was next to it with OR 1.18, OR of $A B$ was 0.69 while $A$ had OR of 0.57 . There was statistically significant relationship of OSMF with blood group $B$ and $p$-value was $(<0.01)$ which is indication that aptients of blood group $B$ have higher chances to develop OSMF. (Table II)

Table 2: Relationship between OSF and $A B O$ blood group exhibited by Odds Ratio.

\begin{tabular}{|l|l|l|l|l|}
\hline $\begin{array}{l}\text { Blood } \\
\text { Group }\end{array}$ & Odds & $95 \% \mathrm{Cl}$ & p-value \\
\cline { 3 - 4 } & Ratio & Lower & Upper & \\
\hline O & 1.18 & 0.96 & 1.40 & \\
\hline A & 0.57 & 0.42 & 0.72 & \multirow{2}{*}{$<0.01$} \\
\hline B & 2.18 & 1.97 & 2.39 & \\
\hline AB & 0.69 & 0.58 & 0.89 & \\
\hline
\end{tabular}

\section{DISCUSSION}

The objective of considering the affiliation among individual hereditary pattern and disease pathology is the existing area of attention for the scientists. ${ }^{8}$ The effort to create a precise connection among different pathologies and $A B O$ blood group has long relation of 20th century. Resultantly,
Karl Landsteiner found $\mathrm{ABO}$ blood group antigens. $\mathrm{ABO}$ blood group is hereditarily revealed and consequently is not a changeable hazardous cause as smoking, diet, BMI, or additional daily life associated factors. ${ }^{9}$ The increased number potential malignant disorders and oral malignancy significantly associated with mortality and morbidity have multifarious aetiolgoy along with genetic and environmental factors, hereditary traits and lifestyles. Alcohol consumption and use of tobacco is cause of about $90 \%$ of oral cancers.

The current research revealed that there exist an association between ABO blood groups and OSMF. In this study individuals with B blood group were observed with increased propensity to have OSMF. Blood group antigens are found on oral epithelial cells also besides their presence on red cell membranes. ${ }^{10,11}$

In present research, among the OSMF cases, the female to male ratio was around 1:2. The greatest incidence of OSMF cases irrespective of blood groups was observed in the age set between 18-40years which is in accordance with the results shown in a study by Gheena \& Jain. ${ }^{12}$ The prevalence of OSMF was more observed in patients with blood group B though areca nut chewing habits were noticed among participants of all blood groups. It is because, glycoconjugates make up RBC cell membrane and it also include carbohydrates like $A B O$ antigens that consists of key receptor molecules i.e CD44, integrin, cadherin and EGF receptors for controlling cell motility and proliferation. However, there is variation in expression of these receptors owing to carcinogenic agents like arecoline. The results are in contrary to the findings of Joshi who concluded that blood group $A$ is more likely associated with the probability of developing grade I and grade II OSMF; likewise individuals with blood group B is likely to be associated with grade III OSMF cases. ${ }^{13}$

Findings of our study have very close matching with results reported by Nikam et al. who in OSMF cases established high incidence of $B$ blood group (48\%), next to them were $\mathrm{O}(24 \%), \mathrm{A}(18 \%)$ and lastly $\mathrm{AB}(10 \%) .{ }^{14}$ In a retrospective study by Pradhuman et al blood group $A$ was linked with the oral cancer in most of the cases $(52.1 \%)$ whereas our study observed blood group B in oral premalignant cases. ${ }^{15}$ In another contrary study by Vaish et al they established that individuals with blood group $A$ are greatly vulnerable to premalignant conditions like OSMF and oral lichen planus (OLP), followed by $O, A B$, and $B$ in rational series ${ }^{16}$. Ramesh \& colleagues conducted a study on people with habit of chewing tobacco and concluded that individuals with blood groups $\mathrm{B}+\mathrm{ve}$ and $\mathrm{O}+\mathrm{ve}$ can be appraised to have more likeness to develop oral cancer. ${ }^{17}$ Ashwinirani and co-researcher conducted a study to evaluate the association between blood groups and oral carcinomas to conclude that people with blood group $A$ were more prone to develop oral carcinoma. ${ }^{18}$

Further studies are recommended to be conducted on large sample size for further confirming role of $A B O$ blood group which has been totally ignored as a biomarker in different diseases and various stages of OSF.

\section{CONCLUSION}

The current study showed that $\mathrm{ABO}$ blood groups have significant relation with oral submucous fibrosis. Individuals 
having "B" blood group had 2.18 times increased tendency of having oral submucous fibrosis in contrast to other blood groups.

Conflict of Interest: No conflict of interest

Funding Source: No fund or grant provided

\section{REFERENCES}

1. Reddy VKG, Moon NJ, Sharva V, Prasad G, Reddy EK, Chandralkala $S$. Is there an association between oral submucous fibrosis and ABO blood grouping? I Can Res Ther. 2016;12(1):126-30.

2. Rao NR, Villa A, More CB, Jayasinghe RD, Ker AS, Johnson NW. Oral submucous fibrosis: a contemporary narrative review with a proposed inter-professional approach for an early diagnosis and clinical management. J Otolaryngol Head N Surg. 2020;49(3):399-409.

3. More C, Shilu K, Gavli N, Rao NR. Etiopathogenesis and clinical manifestations of oral submucous fibrosis, a potentially malignant disorder: an update. Int $\mathrm{J}$ Curr Res. 2018;10(07):71816-20.

4. Mohiuddin S, Fatima N, Hosein S, Hosein M. High risk of malignant transformation of oral submucous fibrosis in Pakistani females. J Pak Med Assoc. 2016;66(11):1362-66.

5. More C, Peter R, Nishma G, Chen Y, Rao N. Association of Candida species with Oral submucous fibrosis and Oral leukoplakia: a case control study. Ann Clin Lab Res. 2018;06(3):248

6. Arakeri G, Patil SG, Aljabab AS, Lin KC, Merkx MA, Gao S, et al. Oral submucous fibrosis: an update on pathophysiology of malignant transformation. J Oral Pathol Med. 2017;46(6):413-7

7. Singh A, Purohit BM. ABO Blood Groups and Its Association with Oral Cancer, Oral Potentially Malignant Disorders and Oral Submucous Fibrosis- A Systematic Review and MetaAnalysis. Asian Pac J cancer Prev. 2021;22(6):1703-12.

8. Reddy VKG, Moon NJ, Sharva V, Guruprasad, Reddy EK, Chandralkala $S$. Is there an association between oral submucous fibrosis and $\mathrm{ABO}$ blood grouping? J Can Res Ther 2016; 12(1): 126-30.

9. Greer JB, Yazer MH, Raval JS, Barmada MM, Brand RE, Whitcomb DC. Significant association between ABO blood groups and pancreatic cancer. World J Gastroenterol 2010;16:5588-91.

10. Phulari, Rashmi DS, Dave, Esha J. A systematic review on the mechanisms of malignant transformation of oral submucous fibrosis. Eur J Cancer Prev. 2020;29(5):470-3.

11. Priyadharshani R, Ekanayaka and Tilakaratne WM. Oral Sub mucous Fibrosis: Review on Mechanisms of Pathogenesis and Malignant Transformation. J Carcinogen Mutagens 2013:1-11

12. Gheena KT, Jain SRK. Age and gender predilection of oral submucous fibrosis in an outpatient population of a dental college- a retrospective study. J Contemp Issues Busi Gov. 2021;27(2):2996-3003.

13. Joshi $A$. ABO blood groups and rh factor association with oral submucous fibrosis: a clinical short study in jodhpur population. Int J Med Sci Diag Res. 2019;3(8):76-80.

14. Nikam P, Bommanavar S, Malik S, Gugwad S, Baad R. Evaluation of $A B O$ blood group system in patients suffering from oral submucous fibrosis. Int J Curr Res. 2015; 7(3):13295-8.

15. Verma P, Kumar A, Dixit S, Mohan K, Gupta N, Mandal G. Assessment of relationship of $A B O$ blood groups in oral cancer patients - a retrospective study. Ann Maxillofac Surg. 2021;11(1):80-5.

16. Ramesh G, Pathak S, Gupta B, Raj A, Pathak R. Is blood group an important factor in oral cancer? - A Review. Rama Univ J Dent Sci. 2015;2(4):17-22.

17. Gayathri R, Anuradha K, Amrita R, Amit K, Ramesh N, Amit $\mathrm{P}$. Assessment of relationship of $\mathrm{ABO}$ blood groups among tobacco induced oral cancer patients of Kanpur Population, Uttar Pradesh. J Exp Ther Oncol. 2017;12(2):129-35.

18. Ashwinirani SR, Suragimath G. Association between oral cancer and ABO blood groups. J Datta Meghe Inst Med Sci Univ. 2021;16:76-9. 